G. DUMITRU
V. ROMANO
1,
H.P. WEBER
Y. $^{1}$
YERBIG $^{2}$
H. HAEFKE
S. BRUNEAU
S. HERMANN
J. HENTIS $^{3}$
M. SENTI

G. DUMITRU ${ }^{1, \otimes, *}$

V. ROMANO

H.P. WEBER

Y. GERBIG ${ }^{2}$

H. HAEFKE ${ }^{2}$

S. BRUNEAU ${ }^{3}$

M. SENTIS ${ }^{3}$

\section{Femtosecond laser ablation of cemented carbides: properties and tribological applications}

\author{
${ }^{1}$ Institute of Applied Physics, University of Bern, Sidlerstrasse 5, 3012 Bern, Switzerland \\ ${ }^{2}$ CSEM Swiss Centre for Electronics and Microtechnology Inc., Jaquet Droz 1, 2007 Neuchâtel, Switzerland \\ ${ }^{3}$ LP3 FRE2165 CNRS-University of Marseille, Luminy, PO Box 917, 13288 Marseille, France
}

Received: 1 December 2003 /Accepted: 4 February 2004 Published online: 1 April 2004 • (C) Springer-Verlag 2004

ABSTRACT Laser ablation with fs laser pulses was performed in air on cobalt cemented tungsten carbide by means of a $\mathrm{Ti}$ : sapphire laser $(800 \mathrm{~nm}, 100 \mathrm{fs})$. Small and moderate fluences $\left(2,5,10 \mathrm{~J} / \mathrm{cm}^{2}\right)$ and up to $5 \times 10^{4}$ pulses per irradiated spot were used to drill holes with aspect ratios up to 10 . Crosssection cuts from laser-irradiated samples were produced and they were analysed with optical microscopy and SEM. EDX analyses were carried out on selected zones. Quasi-cylindrical holes were found for $2 \mathrm{~J} / \mathrm{cm}^{2}$, whereas for 5 and $10 \mathrm{~J} / \mathrm{cm}^{2}$ irregular shapes (lobes, bottoms wider than hole entrances) were found to occur after a given number of incident pulses. Layers with modified structure were evidenced at pore walls. SEM revealed a denser structure, while EDX analyses showed uniform and almost similar contents of W, C, and Co in these layers. As a direct application, patterning of coated WC-Co was carried out with $2 \mathrm{~J} / \mathrm{cm}^{2}$ and 100 pulses per pore. The resulted surfaces were tribologically tested and these tests revealed an improved friction and wear behaviour.

PACS 42.65.Cs; 79.60.Ds

\section{1}

Introduction

Laser ablation is a valuable processing technique in the case of hard and ultrahard materials, whose machining by chip-removal techniques is nearly not possible. Cobalt cemented tungsten carbides (WC-Co) belong to such hard and wear resistant materials and they are widely used in applications like: abrasive tools, metal cutting, injection moulds, rock drilling, tribological surfaces [1]. Particularities of the laser ablation of WC-Co with ns pulses are reported in literature $[2,3]$ and we reported on basic features of the fs-ablation regime (e.g., ablation threshold of $\sim 0.4 \mathrm{~J} / \mathrm{cm}^{2}$ ) in [4]. In previous studies we revealed also that a debris-free fs-laser processing in air can be achieved if fluences below $5 \mathrm{~J} / \mathrm{cm}^{2}$ are used [5].

In this work, pore shape changes occurring during deepdrilling in WC-Co are initially addressed. The occurrence of

Fax: +41-56/462-4151, E-mail: g.dumitru@fh-aargau.ch

* Present address: University of Applied Sciences Aargau, Steinackerstr. 5, CH-5210 Windisch, Switzerland
PLD-like layers (pulsed laser deposition) of redeposited material at pore walls is discussed afterwards and results of analyses carried out on such layers are given. In a last part, the tribological role of pores that were ablated in coated WC-Co substrates is treated.

\section{$2 \quad$ Experiments 2.1 Materials}

Cobalt cemented tungsten carbide consists of hard and brittle WC grains imbedded in a soft and ductile Co binder. This material is sintered at temperatures around $1400^{\circ} \mathrm{C}$, where the interacting phases are $\mathrm{WC}$ grains and molten Co; yet, a limited amount of WC is dissolved in Co. Upon cooling, $\mathrm{W}$ and $\mathrm{C}$ re-precipitate onto WC grains. Depending on the carbon activity during sintering, different amounts of WC may be retained in the Co binder at room temperature: from less than $1 \mathrm{wt}$. $\%$ for $\mathrm{C}$ activities close to 1 [1], up to around $10 \mathrm{wt}$ \% $\mathrm{W}$ for low $\mathrm{C}$ activities [6].

The particular cemented carbide used in the here described experiments had a Co amount of $10 \mathrm{wt} . \%$ and its embedded WC grains had a mean size of $0.8 \mu \mathrm{m}$.

\subsection{Laser experiments}

Investigations were carried out with a $\mathrm{Ti}$ : sapphire laser, delivering $100 \mathrm{fs}$ pulses at a repetition rate of $1 \mathrm{kHz}$. The laser beam was attenuated and then focused using a $20 \times$ microscope objective, which was kept fixed during laser drilling. The spot diameter on the irradiated surfaces was $25 \mu \mathrm{m}$. Deep drilling experiments were carried out at three fluences $(2,5$, $10 \mathrm{~J} / \mathrm{cm}^{2}$ ) and with up to $5 \times 10^{4}$ pulses per irradiated spot. Surface patterning was performed on TiCN coated WC-Co, with $2 \mathrm{~J} / \mathrm{cm}^{2}$ and 100 pulses per hole. In the later case, adjacent pores were spaced by $75 \mu \mathrm{m}$.

\subsection{Sample preparation and analyses}

Cross-section cuts were made through laserirradiated WC-Co samples (both uncoated and coated). The new surfaces were ground and gradually polished. Both initial surfaces and resulted cross-sections were analysed using phase contrast optical microscopy (OM) and scanning electron microscopy (SEM). On selected zones, energy dispersive $\mathrm{X}$-ray (EDX) investigations were performed. 


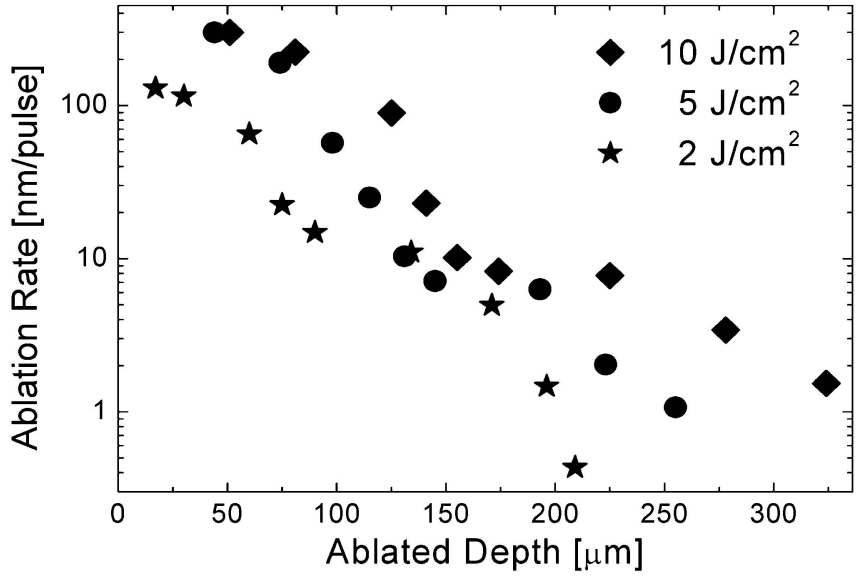

FIGURE 1 Ablated depths for various pulse numbers

\section{4}

\section{Tribology}

Reciprocating sliding tests were performed on patterned coated WC-Co using a linear-oscillation tribometer with a steel counter body. The contact pressure was $250 \mathrm{~N} / \mathrm{mm}^{2}$, comparable to values occurring in metal forming processes [7]. Both SEM and EDX analyses were performed on tribologically tested surfaces.

\section{3 \\ 3.1 \\ Results \\ Deep holes: shape changes}

Quasi-cylindrical hole shapes were obtained for all used fluences if less than $2 \times 10^{3}$ incident pulses were used. In the dependence of the ablated depth vs. the number of incident pulses, one found rapidly increasing depths at the drilling process beginning. With progressing number of pulses the increase of depths was slowly reduced. Similar outcomes were found for other materials $[8,9]$, and it was assumed that this might be connected with the occurrence of 3-D rough structures within the ablation zone (for metals, [8]).

Using the evolution of the ablated depths, ablation rates were derived for each fluence; results are plotted (vs. ablated depth) in Fig. 1. From these graphs one can see that: $i$ the ablated depth per pulse decreases with increasing depths and $i i$ at similar depths, the higher the incident fluence, the larger the ablation rate.

For the used pulse duration, the laser fluence of $10 \mathrm{~J} / \mathrm{cm}^{2}$ corresponds to an intensity value slightly below $10^{14} \mathrm{~W} / \mathrm{cm}^{2}$, a figure that is larger than the air breakdown threshold $\left(\sim 10^{13} \mathrm{~W} / \mathrm{cm}^{2},[10]\right)$. In such cases, plasma occurs in the vicinity of the focal plane and the beam profile undergoes an alteration process (scattering, dispersion) on this plasma. This reduces the fluence in the beam centre and limits the ablation yield. Furthermore, the occurrence of air breakdown limits the precise processing regime: for fluences above this limit, the dispersion phenomena can lead to uncontrollable beam profiles (see Fig. 2, top).

Cross-section cuts corresponding to pores induced with more than $2 \times 10^{3}$ incident pulses are shown in Fig. 2; due to sample preparation, a cross-section through a pore middle includes also a partial cut through an adjacent pore. Quasicylindrical holes were observed at $2 \mathrm{~J} / \mathrm{cm}^{2}$ for all pulse numbers (Fig. 2, bottom). In the case of $5,10 \mathrm{~J} / \mathrm{cm}^{2}$ and after a certain number of pulses $\left(1 \times 10^{4}\right.$ at $5 \mathrm{~J} / \mathrm{cm}^{2}, 5 \times 10^{3}$ at $10 \mathrm{~J} / \mathrm{cm}^{2}$ ), bottom dimensions became larger than entrance diameters and lobes were noticed in hole shapes (Fig. 2, top). This is consistent with the mentioned beam profile alteration and with other experimental observations (steel, [11]). In the

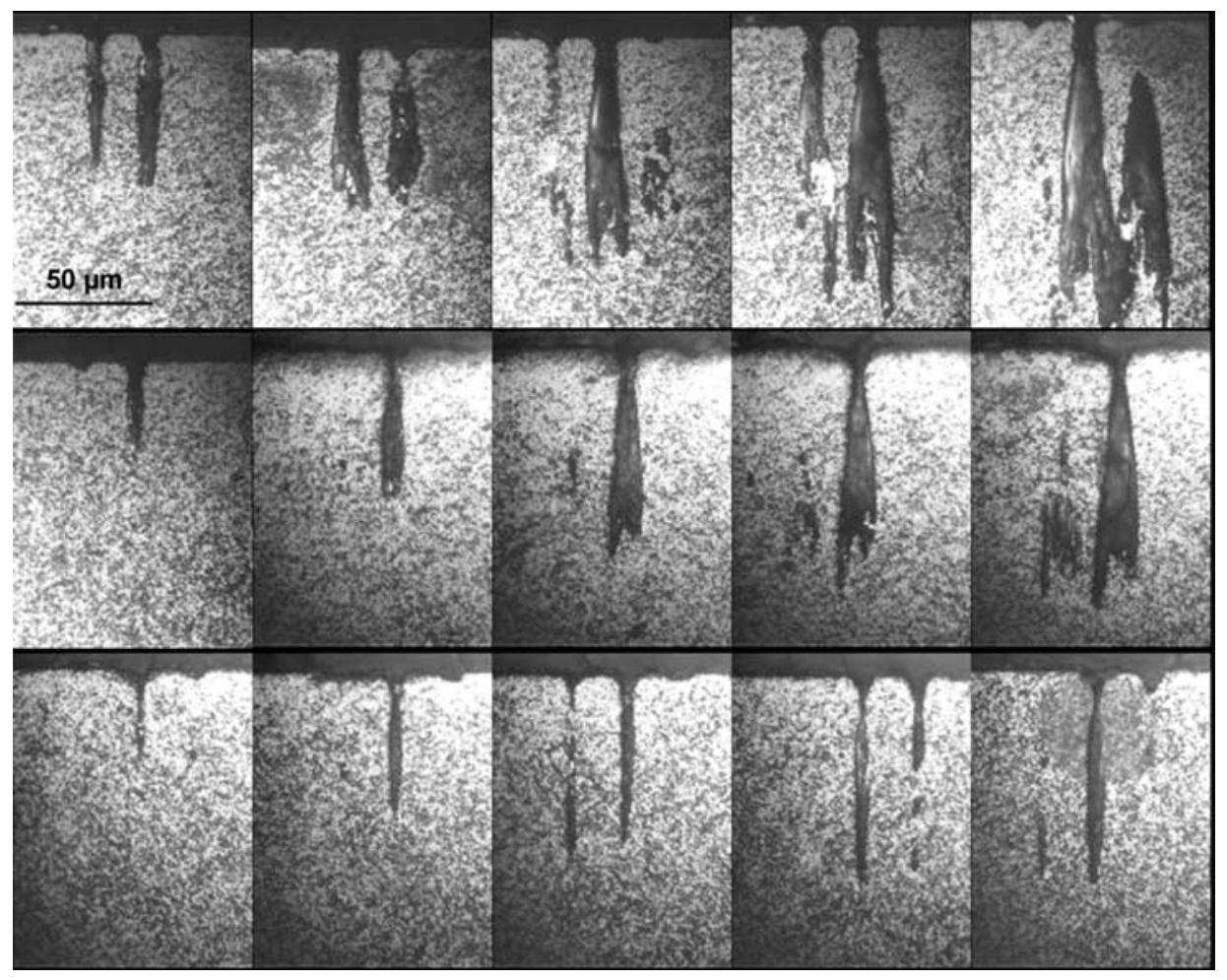

FIGURE 2 Pore geometries for different pulse numbers (from left: $2,5,10,20$, $50 \times 10^{3}$ ) and fluences (from top: 10, 5, $2 \mathrm{~J} / \mathrm{cm}^{2}$ ) 
case of mild ablation regime $\left(2 \mathrm{~J} / \mathrm{cm}^{2}\right)$, a pore narrowing was observed only starting from $2 \times 10^{4}$ pulses, suggesting the possibility of material redeposition near the hole entrance.

\subsection{PLD-like redeposition at pore walls}

SEM analyses of cross-section cuts revealed zones of modified material at pore walls, situated near pore entrances. For illustration, a SEM image from the entrance zone of a hole produced with $5 \mathrm{~J} / \mathrm{cm}^{2}$ and $5 \times 10^{3}$ pulses is shown in Fig. 3. One can notice that the material structure of these layers differs distinctively from WC-Co structure. Furthermore, they were not found to be symmetrically situated; their positions and extensions might suggest a particle trajectory similar to that indicated by the white arrows in Fig. 3. SEM images from the bottom of the hole depicted in Fig. 3 showed no layers of modified material and even partially ablated WC grains were observed.

Structure details can be extracted from Fig. 4a, where a magnified SEM image from such a layer is depicted. One observes a well-defined interface between the sintered WCCo substrate and the new material layer. The latter is denser, has much smaller pores than initial WC-Co and exhibits no grain structure. The distribution of chemical elements was studied by means of EDX: the white line in Fig. 4a is the path, along which the element contents were studied and results are shown in Fig. 4b.

The white line passes through grain interstices in (1) and (2): W content falls and one notices a Co peak. Between (1) and (2) as well as between (2) and (3) the line goes through WC grains and relatively stable $\mathrm{W}$ and Co amounts are measured. After (3) the line enters the new layer and sudden changes can be observed: $\mathrm{W}$ content drops, that of Co increases and both exhibit quasi-identical element counts. This

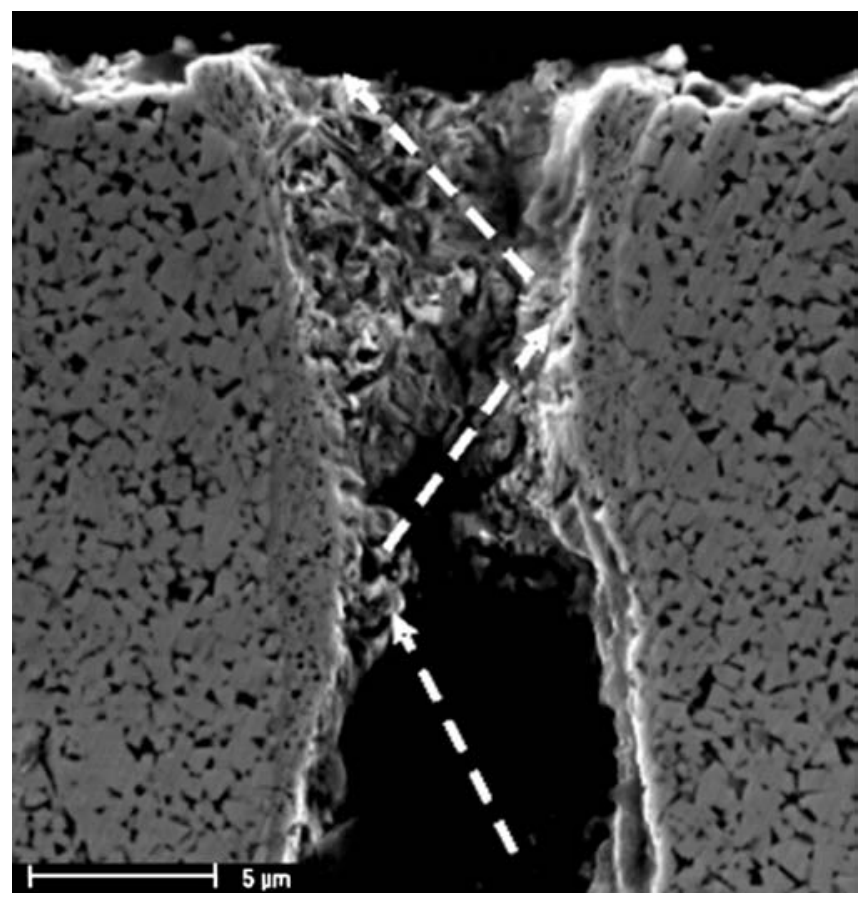

FIGURE 3 SEM images from a hole induced with $5 \times 10^{3} \times 10 \mathrm{~J} / \mathrm{cm}^{2}$ characterises a pulsed laser deposition (PLD) process; based on these results one can assume that a redeposition of material ablated for pore bottom took place at pore walls.

The presence of PLD-like layers was found to depend on incident fluences: at $2 \mathrm{~J} / \mathrm{cm}^{2}$ only a small bottleneck effect occurred after $2 \times 10^{4}$ pulses, whereas for $10 \mathrm{~J} / \mathrm{cm}^{2}$ local re-
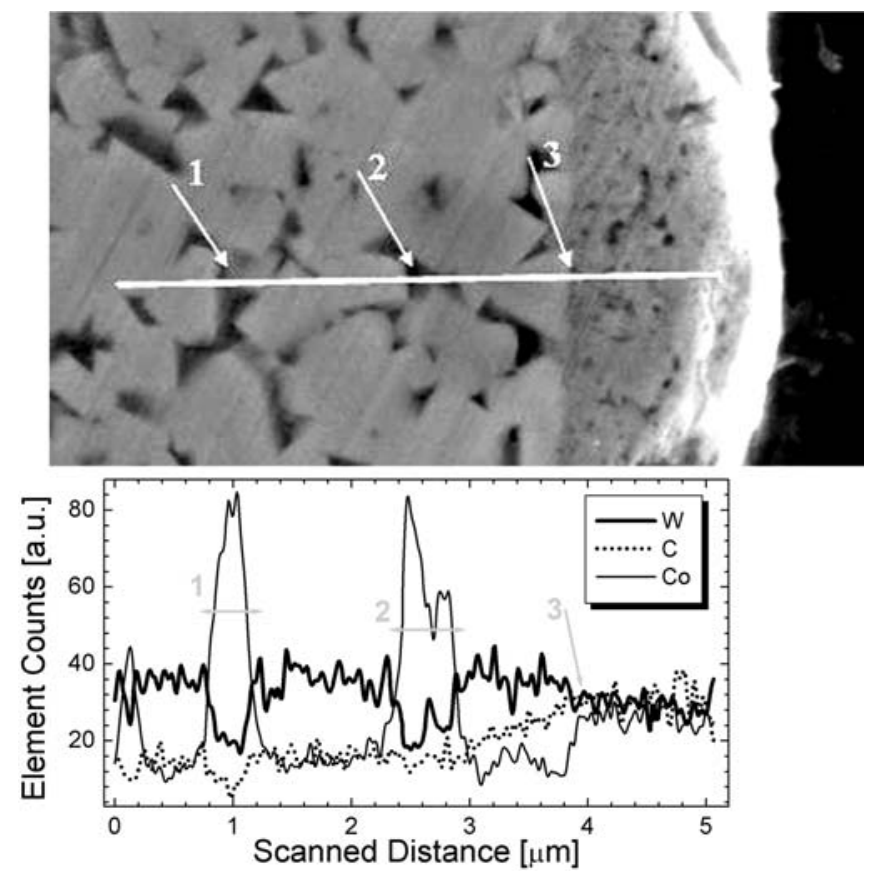

FIGURE 4 Detail from a redeposition layer; top: SEM image and path of EDX analysis, bottom: results of EDX analysis

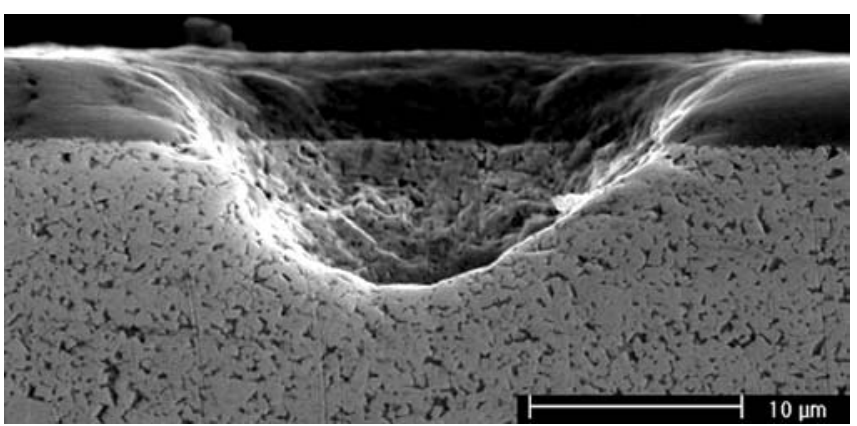

FIGURE 5 Laser ablated pore in coated WC-Co $\left(100 \times 2 \mathrm{~J} / \mathrm{cm}^{2}\right)$

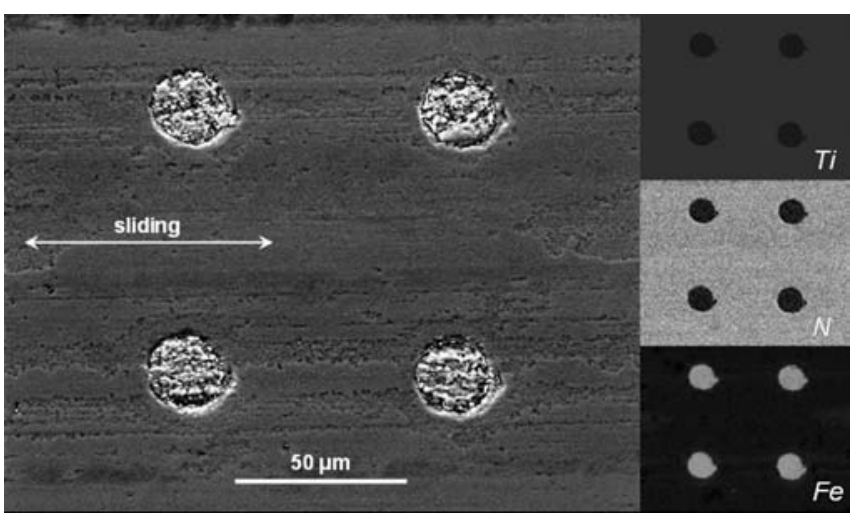

FIGURE 6 SEM image from wear track and corresponding EDX mappings of $\mathrm{Ti}, \mathrm{N}$, and $\mathrm{Fe}$ 
deposited layers were observed even in the beginning phase of the drilling process. The higher kinetic energies of the removed particles (related to larger incident fluences) allowed them to penetrate into the WC-Co substrate and to locally build PLD-like layers.

\subsection{Results on coated $\mathrm{WC}-\mathrm{Co}$}

SEM analyses showed (Fig. 5) smooth filmsubstrate transitions, without any spikes or sharp rims; on the pore bottom one could notice still separated WC grains. This characterises an intrusion-free processing, possible in the mild ablation regime. Furthermore, no film cracks or delaminations were observed: the patterned surfaces could be tribologically tested directly after the laser processing.

Tribological tests demonstrated improved $[12,13]$ wear behaviours for the patterned coated WC-Co surfaces. SEM analyses performed on tribo-tested surfaces showed (Fig. 6) uninterrupted coatings and partially filled up pores. The coating $(\mathrm{TiCN})$ uniformity was also evidenced by EDX: no dark points apart from pores (Fig. 6) appear in Ti and N mappings. The pores were found to be filled up with $\mathrm{Fe}$ from the test counter body; this illustrates the particle trap role of the laserinduced pores.

\section{4}

\section{Conclusions}

Drilling in WC-Co by laser ablation with up to $5 \times 10^{4}$ pulses led to quasi-cylindrical hole shapes (aspect ratio $<10$ ) for $2 \mathrm{~J} / \mathrm{cm}^{2}$. For 5 and $10 \mathrm{~J} / \mathrm{cm}^{2}$ divergent hole shapes and lobes were observed after a certain number of pulses $\left(1 \times 10^{4}\right.$ and $5 \times 10^{3}$, respectively).

A plasma-induced beam profile alteration, occurring at laser intensities above air breakdown threshold is assumed to be the cause of the noticed shape changes. This limits also the domain of incident fluences (in air), where a totally precise and reproducible fs-laser processing is possible.

The occurrence of local redeposited material layers at pore walls was evidenced for 5 and $10 \mathrm{~J} / \mathrm{cm}^{2}$. It was also shown that a well-defined interface separates such a layer from the WC-Co substrate and that its structure corresponds to a PLD process.

Using the mild ablation regime, we demonstrated that the laser ablation of coated WC-Co did not affect the protective films, but improved the friction and wear behaviour of the coated surface.

ACKNOWLEDGEMENTS G. Dumitru acknowledges the support received from the University of Applied Sciences Aargau during the final phase of manuscript preparation.

\section{REFERENCES}

1 G.S. Upadhyaya: Nature and properties of refractory carbides(Nova Science Publishers, NewYork, 1996)

2 D. Bleiner, A. Plotnikov, C. Vogt, K. Wetzig, D. Günther: Fresenius J. Anal. Chem. 368, 221 (2000)

3 T. Li, Q. Lou, J. Dong, Y. Wei, J. Liu: Appl. Phys. A 73, 391 (2001)

4 G. Dumitru, V. Romano, H.P. Weber, M. Sentis, W. Marine: Appl. Phys. A 74, 729 (2002)

5 G. Dumitru, V. Romano, H.P. Weber, M. Sentis, J. Hermann, S. Bruneau, W. Marine, H. Haefke, Y. Gerbig: Appl. Surf. Sci. 208, 181 (2003)

6 M. Hellsing: Mater. Sci. Technol. 4, 824 (1988)

7 J. Bech, N. Bay, M. Erkisen: Wear 232, 134 (1999)

8 A.E. Wynne, B.C. Stuart: Appl. Phys. A 76, 373 (2003)

9 D. Ashkenasi, A. Rosenfeld, H. Varel, M. Wähmer, E.E.B. Campbell: Appl. Surf. Sci. 65120 (1997)

10 D. von der Linde, H. Schüler: J. Opt. Soc. Am. 13, 216 (1996)

11 F. Dausinger: Proc. SPIE 4830, 471 (2003)

12 G. Dumitru, V. Romano, H.P. Weber, H. Haefke, Y. Gerbig: Proceedings of Laser 2001 World of Photonics, München, June 2001; Subconference Lasers in Manufacturing, Editor: WLT eV, p. 351 (2001)

13 G. Dumitru, V. Romano, Y. Gerbig, H.P. Weber, H. Haefke: Appl. Phys. A, DOI 10.1007/s00339-003-2349-4 (2004) 